\title{
Sexual addiction in drug addicts: The impact of drug of choice and poly-addiction
}

\author{
Nelson Antonio ${ }^{1 *}$, Alessandra Diehl ${ }^{2}$, Marcelo Niel ${ }^{1}$, Sandra Pillon ${ }^{3}$, lilian Ratto ${ }^{1}$, Maria Carolina Pinheiro ${ }^{1}$, \\ Dartiu Silveira ${ }^{4}$, Thais Zelia Otani ${ }^{1}$, Victor Otani ${ }^{1}$, Quirino Cordeiro ${ }^{1}$, Ricardo Ushida ${ }^{1}$ \\ 'Center for Integrated Mental Health (CAISM), Faculdade de Ciências Médicas da Santa Casa de São Paulo (FCMSCSP), São Paulo, SP, Brazil \\ 2Psychiatric Department. Sexuality Studies Group (Gesex), Universidade Federal de São Paulo (Unifesp), São Paulo, SP, Brazil \\ ${ }^{3}$ Psychiatric Nursing and Social Science Department, Escola de Enfermagem de Ribeirão Preto da Universidade de São Paulo, Ribeirão Preto, SP, Brazil \\ ${ }^{4}$ Psychiatric Department, Unifesp, São Paulo, SP, Brazi
}

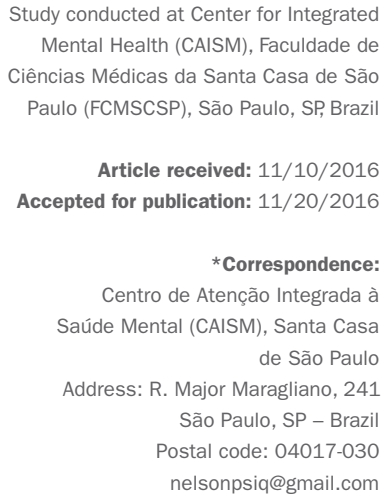

Article received: $11 / 10 / 2016$ Accepted for publication: $11 / 20 / 2016$

*Correspondence: Centro de Atenção Integrada à Saúde Mental (CAISM), Santa Casa de São Paulo

Address: R. Major Maragliano, 241 São Paulo, SP - Brazil Postal code: 04017-030 nelsonpsiq@gmail.com

http://dx.doi.org/10.1590/1806-9282.63.05.414

\section{SUMmARY}

Objective: To compare the risk of comorbid sexual addiction in a sample of individuals with a diagnosis of substance dependence, stratifying the sample by drug of choice as well as by mono versus polysubstance addiction.

Method: All data were collected at Santa Casa de São Paulo, Brazil. The study sample comprised all alcohol or drug dependents admitted to the Addiction Treatment Unit between November 2013 and August 2014. A generalized linear model with a binomial distribution was performed to compare the odds of having a Sexual Addiction Screening Test (SAST) score greater than 6 points in the subgroups analyzed.

Results: A total of 133 participants were included in our analysis, all reporting cocaine/crack and/or alcohol as drug of choice. Polysubstance addicts had a significant higher risk of a positive screening for sexual addiction compared to monosubstance addicts, age-sex adjusted odds ratios of sexual addiction being respectively 2.72 (95CI 1.1-6.71) and 0.37 (95CI 0.15-0.91). The odds of a SAST score greater than 6 was not statistically different between the cocaine/crack and alcohol groups, respectively 0.38 (95CI 0.14-1.02) and 2.67 (95CI 0.98-7.25). We found a significant relation between stronger drug addiction and greater levels of sexual addiction in the cocaine/crack group $(\mathrm{p}=0.0012)$, but not in the alcohol group.

Conclusion: Our study reinforces the importance of assessing sexual behavior of drug addicts in clinical practice, especially considering users of multiple substances or with severe dependence.

Keywords: substance-related disorders, sexual behavior, observational study as topic.

\section{INTRODUCTION}

The condition known as sexual addiction, sexual compulsion or hypersexuality is associated with a number of negative outcomes such as psychological distress, risky sexual behaviors, impairment in interpersonal relationships, and decreased professional performance. Although some authors point to a high prevalence, estimated rates being $2 \%$ in young adults, there is scarce scientific evidence on the underlying nature of this condition. ${ }^{1}$ This lack of knowledge justifies the controversy over the nomenclature, each label implying different assumptions on etiological mechanisms. ${ }^{2}$
Due to similarities with substance addictions, many authors consider sexual addiction as the most appropriate denomination. In this article, we use the terms addiction and dependence interchangeably. ${ }^{3,4}$ Also in support of this concept, sexual addiction is highly frequent in alcohol or drug dependents, prevalence of a dual diagnosis being reported as $25 \% .^{5}$ Despite the previously described connections between the conditions and potential treatment implications, few studies have assessed the risk of sexual addiction among individuals with substance addiction, specially when it comes to different drugs of choice or usage patterns. 
Sexual addiction has been characterized as the engagement in excessive, repetitive sexual activities, including sex-related thoughts, masturbation and pursuing new sexual partners. The use of pornographic material to obtain sexual arousal is also very frequent, as well as seeking professional sex workers. Although this disorder is common and might lead to severe adverse consequences, there is no conclusive evidence on the underlying theoretical framework. Authors who support a sexual addictionmodel point to similar clinical features between sexual and chemical addictions, including the escalating pattern, persistence despite adverse consequences, and repeated and unsuccessful efforts to reduce these behaviors. ${ }^{6}$ There is also growing evidence on a common etiologic basis for the reinforcement effect of drugs and sex, with studies supporting the contribution of the same neurophysiological structures and similar patterns of neuroplasticity over time. ${ }^{78}$ Furthermore, many therapeutic approaches for sexual addiction incorporate elements of addiction-based treatments such as relapse prevention-focused psychotherapy and mutual-help programs with a 12-step format. ${ }^{9}$ Previous reports also suggested that topiramate and naltrexone, medications used for the treatment of some types of substance addiction, may have a therapeutic effect in sexually addicted patients. ${ }^{10}$

Of prognostic relevance, studies with substance addicts have described that sexual addiction is associated with increased relapse rates. One possible explanation is that both addictions are often complementary, many addicts reporting the simultaneous use of substances and sex to experience an enhanced effect. Another common pattern is the shifting between different addictive behaviors during treatment, or using one dependence to counteract withdrawal symptoms from the other. There are also reports on patients using alcohol and drugs to either facilitate sexual behavior or to handle feelings of shame and guilt derived from their sexual practices. ${ }^{8,11}$ Importantly, both sexual addiction and drug use have been associated with increased risk of HIV transmission and other sexually transmitted diseases (STDs). ${ }^{12,13}$ Although more studies are needed to estimate the rates of STDs among individuals concomitantly addicted to substances and sex, this population presents several vulnerability factors, making their study of interest since they will require public health strategies specific for each condition.

Considering the concepts of sexual and substance addiction as an integrated paradigm may support the development of more effective treatment approaches for individuals with both diagnoses. Prior to the implementation of targeted strategies, however, it is important to determine which specific substances or usage patterns might be associated with a higher risk of sexual addiction. Although previous studies have been conducted describing the rates of substance addiction among sexually addicted subjects, few authors have compared the risk of comorbid sexual addiction in users of different substances, or among mono versus polysubstance users.

In face of this gap in the literature, our study was designed to assess the risk of comorbid sexual addiction in a sample of substance addicts, stratifying individuals by drug of choice as well as mono versus polysubstance addiction.

\section{Method}

\section{Study design}

This is an observational study to assess the risk of sexual addiction in a sample of individuals diagnosed as having alcohol or substance dependence, stratified by drug of choice and mono versus polysubstance addiction. Our study is described in accordance with the Reporting of Observational Studies in Epidemiology (STROBE) statement. ${ }^{14}$

\section{Setting}

Data were collected at the Addiction Treatment Unit of Santa Casa de São Paulo, a tertiary care teaching hospital located in central São Paulo, Brazil. Our system is a referral center for the metropolitan area of São Paulo, a city with over 20 million inhabitants, while also providing care for patients from the entire state and country. Patient recruitment and data collection processes occurred over a period of nine months, from November 2013 to August 2014.

\section{Ethics}

Our study was approved by the Institutional Review Board of Santa Casa de São Paulo School of Medicine (protocol number CAAE: 15723813.5.0000.5479), informed consent being offered to all potential participants and subsequently signed prior to any study protocol being implemented. Patients did not receive any form of compensation for participating in the study.

\section{Participants}

The study sample comprised all patients consecutively admitted to the Addiction Treatment Unit at Santa Casa de São Paulo. Inclusion criteria were age over 18 years and a diagnosis of alcohol or substance dependence according to the Diagnostic and Statistical Manual of Mental Disorders, IV Edition, Text Revision (DSM-IV).${ }^{15} \mathrm{~A}$ total of 139 patients were initially part of the analysis. 


\section{Variables}

The outcome of interest was that of SAST scores. Our main predictors were the diagnosis of alcohol and/or substance dependence, the identification of mono or polysubstance usage (i.e., addiction to more than one substance, including alcohol) and the severity of dependence according to the Short Alcohol Dependence Data (SADD) Questionnaire or the Drug Abuse Screening Test (DAST), as applicable. Nicotine addiction was not included in the polysubstance concept. Potential confounders were selected based on evidence from previous literature combined with clinical judgment. Specifically, we selected age and sex. ${ }^{16}$

\section{Data sources/measurement}

Data collection was performed by the main researcher, assisted by Psychiatry residents specifically trained for this protocol. Initially, a 40-minute psychiatric interview was conducted to investigate the necessary criteria in the DSM IV. Participants were then evaluated through the following self-reported instruments: (1) SAST, which is a 20-item dichotomous scale providing an initial assessment of sexual addiction, previously validated in the Brazilian population, with a suggested cut-off score of six points to account for appropriate sensitivity. This is a lower score compared to the 13-point threshold recommended for the original scale version. ${ }^{17}$ In the Brazilian study, the instrument achieved good sensitivity (0.83), specificity (0.75) and internal consistency (Cronbach's alpha $\left.=0.89^{18}\right) \cdot(2)$ SADD Questionnaire, a 15-item scale developed to indicate the severity of alcohol dependence, graded as: I) 0-9 = mild; II) 10-19 = moderate; III) 20-45 = severe. This scale was tested among Brazilian patients, presenting adequate internal reliability with Cronbach's alpha coefficient $=0.79 .{ }^{19}$ (3) DAST, a 20-item scale designed to evaluate the severity of drug-related problems in the last year, according to the following classification: I) $0=$ no problems; II) $1-5=$ mild; III) $6-10=$ moderate; IV) $11-15=$ substantial; V) 16-20 = severe. This instrument includes questions concerning abuse, dependence, withdrawal (signs and symptoms), social impairment, family relationships, legal implications and medical problems. Satisfactory psychometric measures of reliability and validity were reported, with a Cronbach's alpha coefficient of 0.92. This test, however, has not yet been validated for the Brazilian population. ${ }^{20,21}$

\section{Statistical methods}

Our exploratory analysis started by evaluating distributions, frequencies and percentages for each of the nu- meric and categorical variables. Categorical variables were evaluated for near-zero variation. ${ }^{22}$ Extensive graphical displays were used for both univariate analysis and bivariate associations, accompanied by broader tests such as Maximal Information Coefficient ${ }^{23}$ and Non-negative Matrix Factorization ${ }^{24}$ algorithms for numeric variables. Missing data were explored using a combination of graphical displays involving univariate, bivariate and multivariate methods. Imputation was performed using a $\mathrm{k}$ nearest neighbors algorithm $(\mathrm{n}=5) .^{25}$

A generalized linear model with a binomial distribution (logistic regression) was performed to assess the impact of each predictor variable on the risk of sexual addiction, ultimately assessing the odds ratio of having an SAST score greater than six among individuals with different drugs of choice, as well as between mono versus polysubstance addicts. We also measured the impact of different severity levels of drug dependence using the Pearson's Chi-square test. Results are reported as odd ratios for Boolean outcomes, and predicted means for numeric outcomes, along with 95\% Confidence Intervals (95CI). All analyses were performed using the R language $e^{26}$ and the following packages: ggplot $2,{ }^{27}$ rmarkdown. ${ }^{28}$

\section{Results}

\section{Sample characteristics}

An initial sample size of 139 subjects participated in this analysis. Of these, six individuals who had marijuana as their drug of choice were excluded because of the small sample size, thus leading to a final sample size of 133 subjects. Most of our subjects were single, heterosexual, unemployed males (84.2\%), in their late 30s, with a high-school education level. Regarding drug of choice, 59 subjects indicated preferential use of alcohol (44.4\%), while 74 were primarily users of cocaine/crack (55.6\%). We had no other substances referred to as drugs of choice, though $39.1 \%$ of our sample size comprised polysubstance addicts, smoking being reported by $38.3 \%$ of our subjects (Table 1 ).

Comparing individuals with different drugs of choice, those in the alcohol group were older and had higher rates of unemployment. The majority in this group was classified as having severe addiction through the Alcohol Addiction Scale (50.8\%), with most individuals (84.7\%) being monosubstance addicts. In contrast, most individuals in the cocaine/crack group had substantial drug-related problems, and polysubstance dependence was frequent $(58.1 \%)$.

Considering a SAST cut-off of six points as recommended for the Brazilian population, polysubstance addicts had a significantly higher risk of a positive screening for 
TABLE 1 Sample characteristics stratified by drug of choice.

Variable [Missing]

Age [1]

Gender female [0]

Currently working [16]

Marital status [2]

Divorced/separated

Married

Single

Common law partner

Race [9]

Black

Mixed

White

Sexual orientation [6]

Bisexual

Heterosexual

Homosexual

Income (Brazilian reais) [15]

No income

Up to minimum income

Minimum to 2,000

2,000-5,000

More than 5,000

Education level [1]

No formal education

Primary school

High school

Mid school

University

SAST - Total [34]

SAST higher than 6 [34]

SAST higher than 13 [34]

SADD - Total [31]

SADD - Category [1]

Does not apply

Mild (0-9)

Moderate (10-19)

Severe (20-45)

Type of addiction [0]

Mono-addiction

Poly-addiction

DAST - Total [42]

DAST - Category [0]

Does not apply

Mild (1-5)

Moderate (6-10)

Substantial (11-15)

Severe (16-20)
Total (133)

$37.15( \pm 9.61)$

$21(15.8 \%)$

$52(44.4 \%)$

$26(19.8 \%)$

$19(14.5 \%)$

$74(56.5 \%)$

12 (9.2\%)

15 (12.1\%)

$35(28.2 \%)$

74 (59.7\%)

4 (3.1\%)

$113(89 \%)$

$10(7.9 \%)$

$10(8.5 \%)$

$28(23.7 \%)$

$56(47.5 \%)$

$20(16.9 \%)$

$4(3.4 \%)$

2 (1.5\%)

$12(9.1 \%)$

$63(47.7 \%)$

$25(18.9 \%)$

$30(22.7 \%)$

$5.26( \pm 4.03)$

$32(32.3 \%)$

$5(5.1 \%)$

$17.54( \pm 9.67)$

$32(24.2 \%)$

$26(19.7 \%)$

$33(25 \%)$

41 (31.1\%)

81 (60.9\%)

$52(39.1 \%)$

$12.27( \pm 3.89)$

$42(31.6 \%)$

4 (3\%)

24 (18\%)

37 (27.8\%)

$26(19.5 \%)$
Alcohol (59)

$40.69( \pm 10.47)$

$9(15.3 \%)$

17 (32.7\%)

9 (15.5\%)

15 (25.9\%)

$26(44.8 \%)$

8 (13.8\%)

5 (9.1\%)

$17(30.9 \%)$

33 (60\%)

$0(0 \%)$

$51(92.7 \%)$

$4(7.3 \%)$

$62(8.6 \%)$

$62(86.1 \%)$

$6(8.3 \%)$

$4(8.2 \%)$

$6(8.7 \%)$

$18(36.7 \%)$

$10(14.5 \%)$

$15(30.6 \%)$

$41(59.4 \%)$

$12(24.5 \%)$

0 (0\%)

$8(11.6 \%)$

$4(5.8 \%)$

$0(0 \%)$

$2(3.4 \%)$

$8(10.8 \%)$

4 (6.9\%)

$28(48.3 \%)$

$35(47.3 \%)$

$9(15.5 \%)$

$16(21.6 \%)$

$15(25.9 \%)$

$15(20.3 \%)$

$4.11( \pm 3.33)$

$5.95( \pm 4.27)$

7 (18.9\%)

25 (40.3\%)

$0(0 \%)$

$20.22( \pm 9.85)$

5 (8.1\%)

$13.86( \pm 8.18)$

$0(0 \%)$

$32(43.8 \%)$

$10(16.9 \%)$

$16(21.9 \%)$

19 (32.2\%)

14 (19.2\%)

30 (50.8\%)

$11(15.1 \%)$

50 (84.7\%)

31 (41.9\%)

9 (15.3\%)

$43(58.1 \%)$

$9.76( \pm 4.48)$

$12.85( \pm 3.53)$

$42(71.2 \%)$

$0(0 \%)$

$4(6.8 \%)$

$0(0 \%)$

4 (6.8\%)

$20(27 \%)$

$7(11.9 \%)$

30 (40.5\%)

$2(3.4 \%)$

24 (32.4\%) 
sexual addiction compared to monosubstance addicts (Figure 1), the age and sex-adjusted odds ratio of sexual addiction being respectively 2.72 (95CI 1.1-6.71) and 0.37 (95CI 0.15-0.91). We also found a significant relationship between the severity of drug addiction and the risk of sexual addiction in the cocaine/crack group using the Pearson's Chi-squared test $(\mathrm{p}=0.0012)$ (Figure 2$)$, but a similar trend was not observed in the alcohol group.

An SAST score higher than six was present in 18.9 and $40.3 \%$ of the individuals, respectively, in the alcohol and cocaine/crack groups. Only five individuals had an SAST score higher than 13 , all in the cocaine/crack group. The age-sex adjusted odds for SAST scale higher than six demonstrated no statistically different results between the cocaine/crack and alcohol groups, respectively calculated as 0.38 (95CI 0.14-1.02), and 2.67 (95CI 0.98-7.25). We, however, found no significant differences in the risks of sexual addiction when stratifying the alcohol or cocaine/ crack groups between mono and polysubstance dependence.

\section{Discussion}

To the best of our knowledge, this is the first study comparing the risk of sexual addiction among substance addicts and alcohol or cocaine/crack as their drugs of choice, as well as between mono and polysubstance addicts. Based on the SAST, we found that polysubstance addicts had a higher risk of sexual addiction than monosubstance addicts. There was no significant difference in the risk of sexual addiction of individuals who reported cocaine/ crack versus alcohol as their drug of choice. More severe dependence was a risk factor for sexual addiction only among individuals reporting cocaine/crack as their drug of choice. In our sample, no subjects reported other substances as their drug of choice.

The distribution of drugs of choice in our sample is consistent with studies reporting alcohol and cocaine as popular drugs of abuse in the Brazilian population. Another characteristic reported in the Brazilian population is the infrequent use of heroine, consistent with our analysis in this sample. However, the previously described use of marijuana and solvent inhalants in Brazil was not verified in our sample. ${ }^{29}$ Our findings may reflect differences in the access to health care services among addicts to different substances.

As expected, the prevalence of sexual addiction in our study was higher than the corresponding estimated rates in the general population. Our results are also in agreement with the literature demonstrating that polysubstance addicts have higher rates of psychiatric comorbidities compared with individuals addicted to one substance. ${ }^{30,31}$

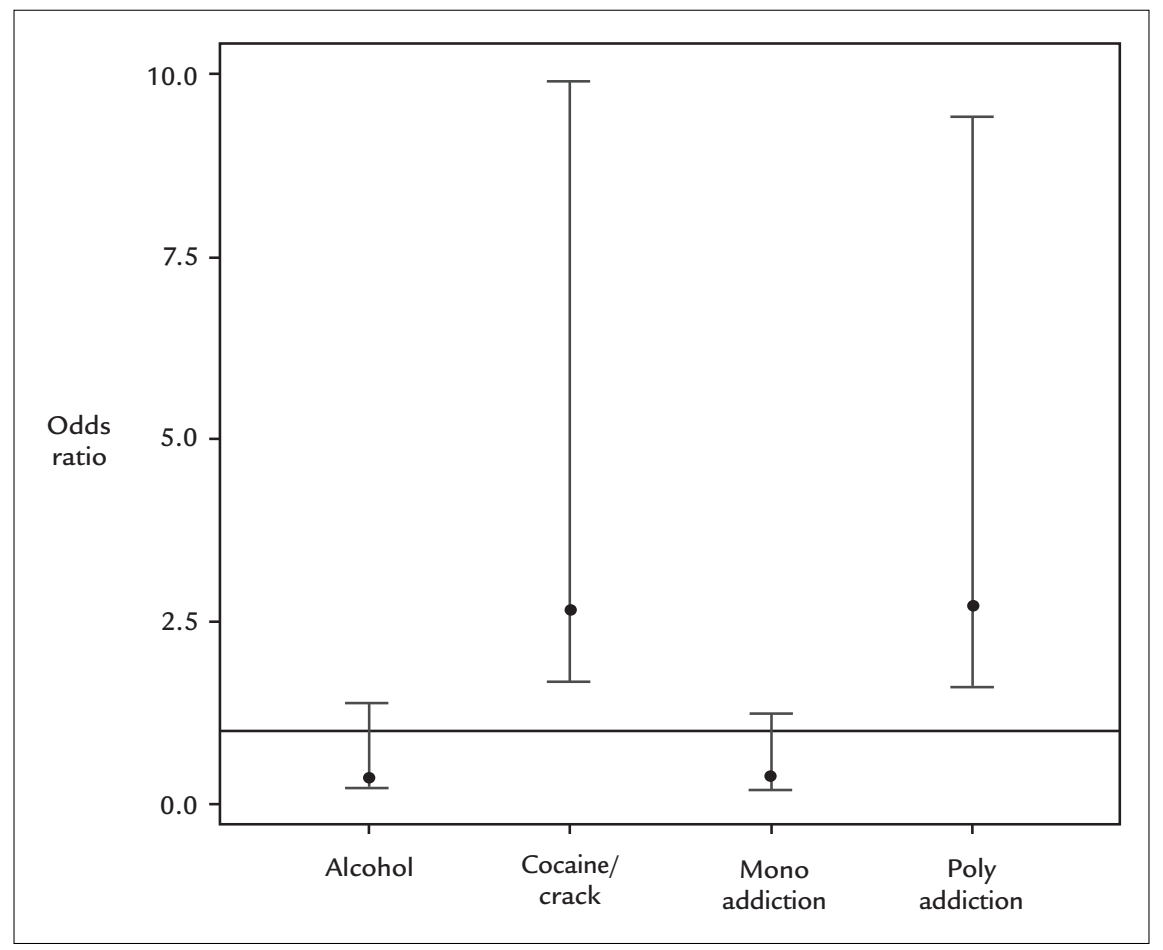

FIGURE 1 Age and sex adjusted odds ratio of having an Sex Addiction Screening Test score higher than six according to drug of choice and mono versus polysubstance addiction, São Paulo, 2013-2014. 


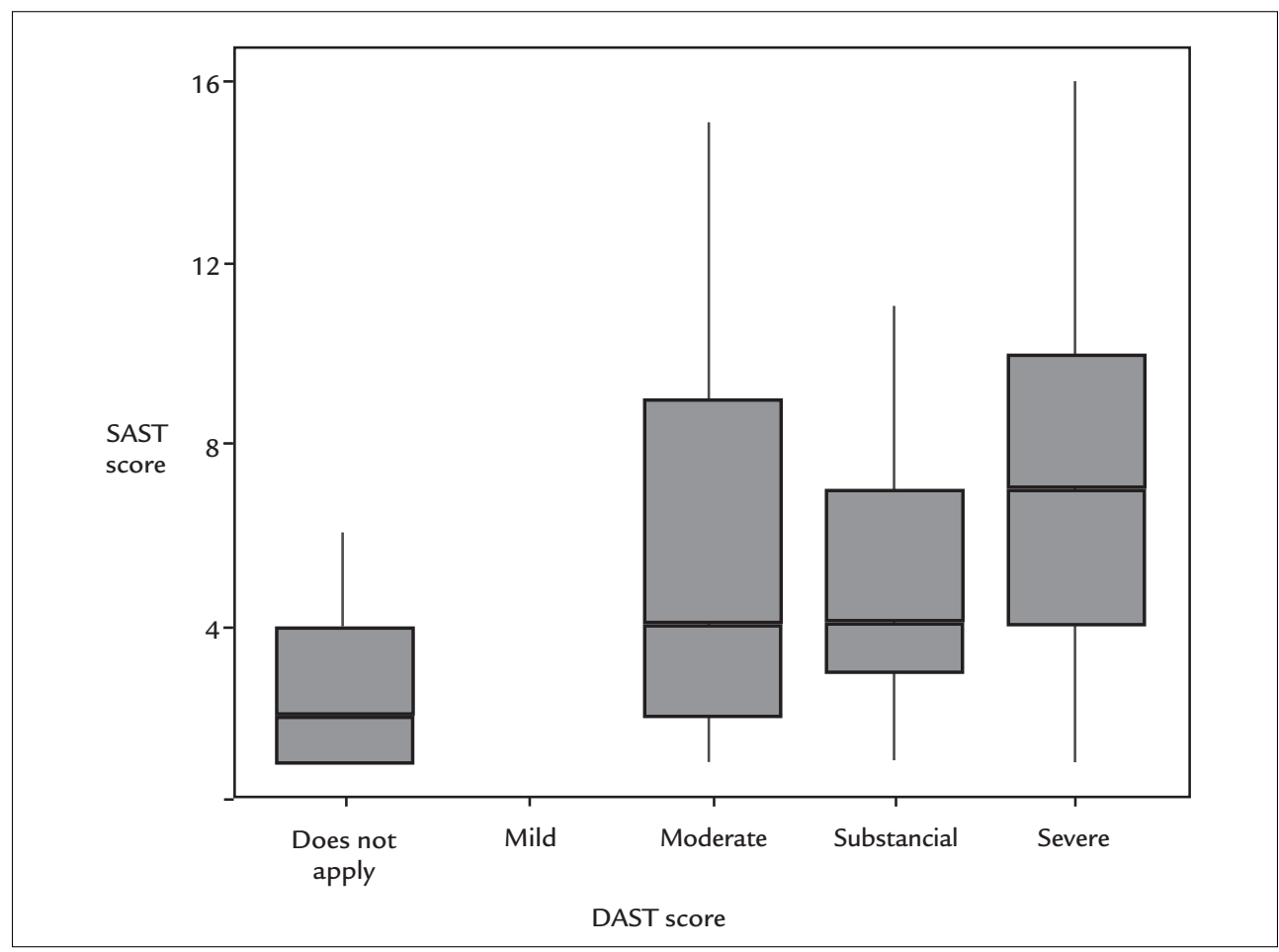

FIGURE 2 Severity of drug-related problems according to the Drug Addiction Screening Test (DAST) and risk of sexual addiction according to the Sex Addiction Screening Test (SAST), São Paulo, 2013-2014.

Furthermore, comparisons of personality profiles among drug addicts demonstrated an increased disturbance pattern when polysubstance addiction is involved. ${ }^{32}$ Considering our findings in this context, it is possible that pre-morbid personality traits associated with polysubstance addiction such as novelty-seeking may predict sexual addiction. ${ }^{33}$

Another possible explanation for the association between polysubstance and sexual addiction might be the influence of socio-cultural contexts where sex, drugs, and alcohol are connected. For instance, dance clubs and circuit parties are environments where the use of multiple substances and the seeking of new sexual partners are common behaviors, possibly eliciting a mutually reinforcing pattern. ${ }^{34}$ Contextual factors might also have a role in the association between severity of drug addiction and increased sexual activity. Heavy substance users might be more vulnerable to the exchange of sex for money or drugs while craving drugs, resulting in a higher number of sexual partners..$^{35,36}$

Interpretations of our results based on the effects of each drug on sexual response must be viewed with caution. According to popular beliefs, cocaine and alcohol are considered aphrodisiac, often being used with the intent of enhancing sexual activity. ${ }^{37}$ Among mild alcohol and cocaine/crack users, increased sexual desire might be caused by transient drug-induced increases in dopaminergic activity, disinhibitory effects and non-pharmacological factors, such as learned behavioral responses and expectations about the sexual effects of drugs. ${ }^{38,39}$ As for the chronic abuse of these substances, the literature demonstrates an association with decreased libido, impairment on sexual performance and sexual dysfunction. ${ }^{40}$ Further research is needed to better understand the direct and indirect impact of each substance on sexual behavior. Several variables should be contemplated, including but not limited to dosage, chronicity of use, gender and psychosocial factors.

Despite filling a gap in the literature, our study does have limitations. First, given that our sample was small and not randomly drawn from a larger patient population, its external validity can be questioned. Nevertheless, our sample is not atypical for its setting, making our conclusions valid for similar populations. Second, our data did not establish the dose-response impact of each type of drug use on the risk of sexual addiction. However, this is a sample of individuals with high levels of substance addiction, thus supporting our results in this context. Finally, although our data have demonstrated that sexual addiction is a significant problem in our sample, we did 
not compare it to a control group of non-substance addicts in our comparison. Although the rates of sexual addiction in our sample are higher than that reported for the general population, future research should address this question.

\section{Conclusion}

Our study reinforces the importance of assessing the sexual behavior of alcohol and drug addicts in clinical practice, especially considering polysubstance users and severe drug addicts. Sexual addiction must be systematically evaluated and addressed within drug rehabilitation programs, given that concurrent treatment may lead to better outcomes. Moreover, substance addicts should be targeted for public health programs focused on the prevention of risky sexual behavior. More studies are needed to understand the neurobiological basis of sexual addiction and its connection to other chemical and behavioral addictions, which may lead to more comprehensive treatment programs.

\section{Resumo}

Dependência sexual em dependentes químicos: o impacto de diferentes drogas de escolha e de polidependência

Objetivo: Comparar o risco de dependência sexual em uma amostra de indivíduos com diagnóstico de dependência química, estratificados por droga de escolha e por dependência única ou de múltiplas substâncias.

Método: Todos os dados foram coletados na Santa Casa de São Paulo, Brasil. A amostra estudada correspondeu a todos os indivíduos dependentes de álcool ou outras substâncias admitidos no Ambulatório de Dependência Química entre novembro de 2013 e agosto de 2014. Modelos lineares generalizados com distribuição binomial foram utilizados para comparar o risco de escores maiores que seis na Escala de Rastreamento para Dependência de Sexo (SAST) nos subgrupos analisados.

Resultados: Foram analisados os dados de 133 pacientes usuários de cocaína/crack e/ou álcool. Usuários de múltiplas substâncias apresentaram risco significativamente maior de um screening positivo para dependência sexual comparados com usuários de uma única substância. Os odds ratios de dependência sexual ajustados por sexo e idade obtidos nos dois grupos foram, respectivamente, 2.72 (IC95\% 1.1-6.71) e 0.37 (IC95\% 0.15-0.91). O risco de dependência sexual entre usuários de cocaína/crack e álcool foi estimado, respectivamente, em 0.38 (IC95\% 0.14-1.02) e 2.67 (IC95\% 0.98-7.25), não indicando diferença signi- ficativa. Foi encontrada uma relação significativa entre severidade de dependência química e maiores níveis de dependência sexual entre dependentes de cocaína/crack, mas não de álcool.

Conclusão: Nosso estudo reforça a importância de avaliar o comportamento sexual de dependentes químicos na prática clínica, especialmente considerando usuários de múltiplas substâncias, ou casos de maior severidade.

Palavras-chave: transtornos relacionados ao uso de substâncias, comportamento sexual, estudos observacionais como assunto.

\section{References}

1. Odlaug BL, Lust K, Schreiber L, Christenson G, Derbyshire K, Harvanko A, et al. Compulsive sexual behavior in young adults. Ann Clin Psychiatry. 2013; 25(3):193-200.

2. Karila L, Wéry A, Weinstein A, Cottencin O, Petit A, Reynaud M, et al. Sexual addiction or hypersexual disorder: Different terms for the same problem? A review of the literature. Curr Pharm Des. 2014; 20(25):4012-20.

3. Kraus SW, Voon V, Potenza MN. Should compulsive sexual behavior be considered an addiction? Addiction. 2016; 111(12):2097-106.

4. Kor A, Fogel YA, Reid RC, Potenza MN. Should hypersexual disorder be classified as an addiction? Sex Addict Compulsivity. 2013; 20(1-2):27-47.

5. Stavro K, Rizkallah E, Dinh-Williams L, Chiasson J-P, Potvin S. Hypersexuality among a substance use disorder population. Sex Addict Compulsivity. 2013; 20(3):210-6.

6. Derbyshire KL, Grant JE. Compulsive sexual behavior: a review of the literature. J Behav Addict. 2015; 4(2):37-43

7. Blum K, Werner T, Carnes S, Carnes P, Bowirrat A, Giordano J, et al. Sex, drugs, and rock ' $n$ ' roll: Hypothesizing common mesolimbic activation as a function of reward gene polymorphisms. J Psychoactive Drugs. 2012; 44(1):38-55.

8. Hartman LI, Ho V, Arbour S, Hambley JM, Lawson P. Sexual addiction and substance addiction: comparing sexual addiction treatment outcomes among clients with and without comorbid substance use disorders. Sex Addict Compulsivity. 2012; 19(4):284-309.

9. Carnes P, Adams KM, editors. Clinical management of sex addiction. New York: Brunner-Routledge; 2013.

10. Leppink EW, Grant JE. Behavioral and pharmacological treatment of compulsive sexual behavior/Problematic hypersexuality. Curr Addict Rep. 2016; 3:406.

11. Punzi EH, Tidefors I, Fahlke C. Excessive sexual activities among male clients in substance abuse treatment. an interview study. Mediterranean J Clin Psychol MJCP. 2014; 2(3) [cited 2016 Jun 5]. Available from: http://cab. unime.it/journals/index.php/MJCP/article/view/1001/pdf_46.

12. Shoptaw S, Montgomery B, Williams CT, El-Bassel N, Aramrattana A, Metsch L, et al. Not just the needle: the state of HIV-prevention science among substance users and future directions. J Acquir Immune Defic Syndr. 2013; 63(Suppl 2):S174-8.

13. Yoon IS, Houang ST, Hirshfield S, Downing MJ. Compulsive sexual behavior and HIV/STI risk: a review of current literature. Curr Addict Rep. 2016; 3:387

14. Von Elm E, Altman DG, Egger M, Pocock SJ, Gøtzsche PC, Vandenbroucke JP; STROBE Initiative. The strengthening the reporting of observational studies in epidemiology (STROBE) statement: guidelines for reporting observational studies. Prev Med. 2007; 45(4):247-51.

15. DSM-IV-TR. American Psychiatric Association; 2000 [cited 2016 Jun 5]. Available from: http://dsm.psychiatryonline.org/doi/abs/10.1176/appi. books.9780890420249.dsm-iv-tr.

16. Scanavino MT, Ventuneac A, Abdo CHN, Tavares H, Amaral MLS, Messina $\mathrm{B}$, et al. Compulsive sexual behavior and psychopathology among treatmentseeking men in São Paulo, Brazil. Psychiatry Res. 2013; 209(3):518-24.

17. Carnes P. Sexual addiction screening test (SAST). Tenn Nurse. 1991; 54(3):29. 
18. Silveira DX, Vieira AC, Palomo V, Silveira ED. [Criteria validity and reliability of the Brazilian version of a sexual addiction screening scale]. Rev Bras Psiquiatr. 2000; 22(1):4-10.

19. Rosa-Oliveira LQ, Presti P de F, Antunes IR, Carbonari GC, Imada AC, Maeda MY, et al. Reliability and dimensionality of the Short Alcohol Dependence Data (SADD) questionnaire in a clinical sample of hospitalized patients: using the SADD in a general hospital setting. Rev Bras Psiquiatr. 2011;33(1):68-71.

20. Skinner HA. The drug abuse screening test. Addict Behav. 1982; 7(4):363-71.

21. Yudko E, Lozhkina O, Fouts A. A comprehensive review of the psychometric properties of the Drug Abuse Screening Test. J Subst Abuse Treat. 2007; 32(2):189-98.

22. Kuhn M, Johnson K. Applied predictive modeling. Springer; 2013.

23. Reshef DN, Reshef YA, Finucane HK, Grossman SR, McVean G, Turnbaugh PJ, et al. Detecting novel associations in large data sets. Science. 2011; 334(6062):1518-24.

24. Paatero P, Tapper U. Positive matrix factorization: a non-negative factor model with optimal utilization of error estimates of data values. Environmetrics. 1994; 5(2):111-26.

25. Prantner B. Visualization of imputed values using the r-package VIM; 2011 [cited 2016 Jun 5]. Available from: https://cran.r-project.org/web/packages/ VIMGUI/vignettes/VIM-Imputation.pdf.

26. R Core Team. R: A language and environment for statistical computing. Vienna, Austria: R Foundation for Statistical Computing; 2015 [cited 2016 Jun 5]. Available from: http://www.r-project.org/.

27. Wickham H. Ggplot2: Elegant graphics for data analysis. Springer Science \& Business Media; 2009

28. Allaire J, Cheng J, Xie Y, McPherson J, Chang W, Allen J, et al. Rmarkdown: Dynamic documents for R. 2015 [cited 2016 Jun 5]. Available from: http:// CRAN.R-project.org/package $=$ rmarkdown

29. Bastos FI, Bertoni N, Hacker MA. Consumo de álcool e drogas: principais achados de pesquisa de âmbito nacional, 2005. Rev Saúde Pública. 2008; 42(Suppl 1):109-17.
30. Salom CL, Betts KS, Williams GM, Najman JM, Alati R. Predictors of comorbid polysubstance use and mental health disorders in young adults-a latent class analysis. Addiction. 2016; 111(1):156-64.

31. Gilder DA, Stouffer GM, Lau P, Ehlers CL. Clinical characteristics of alcohol combined with other substance use disorders in an American Indian community sample. Drug Alcohol Depend. 2016; 161:222-9.

32. Martinotti G, Carli V, Tedeschi D, Giannantonio MD, Roy A, Janiri L, et al. Mono- and polysubstance dependent subjects differ on social factors, childhood trauma, personality, suicidal behaviour, and comorbid axis i diagnoses. Addict Behav. 2009; 34(9):790-3.

33. Koller G, Preuss U, Lü O, Soyka M, Pogarell O. Alcohol-dependent subjects show different personality traits compared with subjects with multiple substance dependence: preliminary data. J Addict Med. 2015; 9(4):257-60.

34. Race K, Lea T, Murphy D, Pienaar K. The future of drugs: recreational drug use and sexual health among gay and other men who have sex with men. Sexual Health; 2016

35. Casanova EG, Lopes GT, Carvalho L de PG, Muzzi AG, Freitas SAB, Ribeiro APLP. Curiosidade, prazer e transgressão: pilares motivadores do consumo de crack. Rev Enferm UERJ. 2015; 23(5):610-5.

36. Nappo SA, Sanchez Z, De Oliveira LG. Crack, AIDS, and women in São Paulo, Brazil. Subst Use Misuse. 2011; 46(4):476-85.

37. Bonito J, Tavares T, Boné M. Social representations about the Portuguese adolescent alcohol consumption. Atención Primaria. 2015; 47(Espec Cong 1):13.

38. Peugh J, Belenko S. Alcohol, drugs and sexual function: a review. J Psychoactive Drugs. 2001; 33(3):223-32

39. Kopetz CE, Reynolds EK, Hart CL, Kruglanski AW, Lejuez C. Social context and perceived effects of drugs on sexual behavior among individuals who use both heroin and cocaine. Exp Clin Psychopharm. 2010; 18(3):214-20

40. Zaazaa A, Bella AJ, Shamloul R. Drug addiction and sexual dysfunction. Endocrinol Metab Clin North Am. 2013; 42(3):585-92. 